\title{
Women's perceptions of antenatal care: are we following guideline recommended care?
}

Amy Waller ${ }^{1,2^{*}}$, Jamie Bryant ${ }^{1,2}$, Emilie Cameron ${ }^{1,2}$, Mohamed Galal ${ }^{3,4}$, Juliana Quay ${ }^{3}$ and Rob Sanson-Fisher ${ }^{1,2}$

\begin{abstract}
Background: Detection and management of antenatal risk factors is critical for improved maternal and infant outcomes. This study describes the proportion of pregnant women who self-reported being screened for and offered advice to manage antenatal risk factors in line with antenatal care recommendations; and the characteristics associated with rates of screening.
\end{abstract}

Methods: A survey was undertaken with 223 (64 \% of eligible) pregnant women recruited from an outpatient obstetrics clinic at a public hospital. Participants self-reported whether they were: (i) screened for 23 guidelinerecommended risk factors during their antenatal visit; (ii) offered assistance to manage identified risk factor(s); and (iii) received assistance that was of benefit. Association between rate of screening and participant characteristics was examined using multivariate quantile regression.

Results: Overall, $23 \%$ of women reported that they were asked about every risk factor. Weight gain (48\%), diet (60 \%) and oral health (31\%) were least frequently screened risk factors. The number of women who reported they were offered advice to manage identified risks and the value of that advice was perceived by women as suboptimal. Those women receiving shared care between a midwife and general practitioner, of Aboriginal or Torres Strait Islander descent, and without private health insurance reported being screened for a greater number of risk factors.

Conclusions: Pregnant women report suboptimal rates of screening and management of antenatal risk factors. Initiatives to improve consistency in detection of antenatal risk factors and the application of appropriate interventions to manage those risk factors that are detected are required.

Keywords: Antenatal, Guidelines, Implementation, Screening, Pregnancy

\section{Background}

A significant gap between best scientific evidence and clinical practice exists across many areas of health care [1]. Previous studies have shown evidence-practice gaps are represented by misuse, underuse or overuse across the health care system [2]. The magnitude of the gap varies across medical conditions, with greater concerns reported in relation to underuse compared to overuse [2]. Developing and implementing strategies that can

\footnotetext{
* Correspondence: amy.waller@newcastle.edu.au

${ }^{1}$ Priority Research Centre for Health Behaviour, University of Newcastle \& Hunter Medical Research Institute, HMRI Building, Callaghan, NSW 2308, Australia

${ }^{2}$ School of Medicine and Public Health, University of Newcastle, Callaghan, NSW, Australia

Full list of author information is available at the end of the article
}

translate evidence into best scientific practice is critical to reduce evidence-practice gaps [3].

Quality of care in maternal services is defined as " $a$ minimum level of care to all pregnant women and their newborn babies and a higher level of care to those who need it" [4]. Disparities in quality of antenatal care have been identified internationally, with low rates of detection of risk factors for poor maternal and perinatal outcomes, including smoking, alcohol consumption, obesity, domestic violence, hypertension and depression reported [5-10]. While evidence-based interventions are available to manage many of these modifiable risk factors [11-13], there are inconsistencies in the application of these interventions for women identified as 'at-risk' [14]. This may occur 
when providers fail to offer appropriate advice, support and/or referrals, or when uptake or adherence to offered treatments is poor $[15,16]$. There are also particular subgroups of vulnerable women for whom interventions may be less effective.

In an attempt to address these disparities, policy and professional organisations have developed antenatal care guidelines that make recommendations about screening across key areas of antenatal care including clinical assessments, maternal and fetal screening and lifestyle behaviours. In Australia, the Australian Health Ministers' Advisory Council released the Clinical Practice Guidelines: Antenatal Care to support clinical decisions about appropriate antenatal care [17]. It is expected that successful implementation of the ANC Guidelines will increase the consistency with which risk factors are identified and treated, and subsequently improve the quality of antenatal care received by pregnant women in Australia.

A key step in reducing evidence-practice gaps is to quantify gaps by systematically measuring current practice and comparing this to recommended practice [18]. Use of medical record audit to quantify the detection and management of risk factors allows data to be drawn from a representative sample [19-21]. However, the accuracy of documentation may be questionable and the perceived benefit of treatments cannot always be ascertained [21, 22]. Providers' perceptions of care may be subject to social desirability reporting and discordant with the views of patients $[10,23]$. While there are potential disadvantages to relying on patient perceptions, including recall bias, they offer potentially a more sensitive measure the perceived value of antenatal care delivered [24]. However, no studies have examined the views of pregnant women living in Australia in relation to whether they were screened for the range of guidelinerecommended antenatal risk factors, the help that was offered and accepted by those identified as 'at-risk', and the perceived benefit of the help that was offered.

\section{Method}

\section{Objective}

To describe the proportion of women who reported that they were: (1) screened for clinical, screening and lifestyle antenatal risk factors by their antenatal care provider during their antenatal visit; (2) offered assistance to manage identified risk factor(s); and (3) that the offered assistance was perceived to be of benefit. Socio-demographic, pregnancy and psychosocial characteristics associated with being screened for antenatal risk factors were also identified.

\section{Sample}

Eligible participants include women who were: currently pregnant, attending the antenatal clinic at a large tertiary public hospital, aged 18 years or older, able to read and understand English, and judged as able to give informed consent and complete the survey. Women needed to have attended at least one previous antenatal visit to ensure an opportunity for screening and offering of assistance by providers.

\section{Procedure}

Eligible women were approached by research staff while waiting for their clinic appointment and invited to participate in the study. Consenting women completed an anonymous survey on a touch screen computer assessing socio-demographic and clinical characteristics, screening and management of risk factors and diet. Only data related to screening and management of risk factors are reported here.

\section{Measures}

\section{Development of survey}

Potentially relevant items were identified from recommendations described in the ANC Guidelines including: clinical, lifestyle and screening risk factors. The format of items were based on similar surveys of quality of care members of the team have utilised to assess quality of care in oncology populations [25]. Items were reviewed by a panel of behavioural scientists and antenatal care providers until consensus was reached about format and content. Items were then pilot tested with a convenience sample of pregnant women $(n=20)$ and modified based on feedback about comprehension and relevance.

\section{Screening and management of risk factors: asked, offered, benefit}

Items examined seven lifestyle; eleven clinical and five screening antenatal risk factors described in the $A N C$ Guidelines.

- Lifestyle factors included: smoking, alcohol intake, recreational drug use, diet, prescription medication, nutritional supplements, oral health.

- Clinical factors included: dating ultrasound, weight, height, BMI, weight gain, blood pressure, urine sample, blood sugar, mental health, anxiety and depression, domestic violence

- Screening factors included: Down syndrome, HIV, Hepatitis B, Rubella, Syphilis.

For each risk factor, women responded to questions about screening and management at the clinic. First, participants were asked whether a health care worker (i.e., an obstetrician, doctor, midwife or nurse) had screened them for the risk factor e.g., "Did your health care worker ask you about your smoking status?" Response options included "Yes", "No but I asked about this,' "No", "Unsure", "Prefer not to answer". Women who 
responded with either "Yes" or "No but I asked about this' were then asked if they were offered any assistance to manage the risk (e.g., "Yes", "No because I am not a smoker" "No"). Those who answered "Yes" were then asked about the type of assistance offered. Examples of assistance were provided for each risk factor. Women were also asked whether the assistance they were offered was of any benefit (e.g., "Yes", "No", "Did not accept help" or "For a short time, but I am smoking again").

\section{Socio-demographic characteristics included}

Date of birth; postcode; Aboriginal or Torres Strait Islander status; marital status; private health insurance status, highest level of education, language spoken at home and country of birth.

\section{Pregnancy characteristics included}

Due date, visits to GP for antenatal care, visits to hospital for antenatal care, weeks of pregnancy at first visit, and number of pregnancies.

\section{Model of care}

Participants were asked to identify the model of antenatal care they received from one of four options: (1) high risk clinic (i.e., doctor-led care for women with certain medical conditions or complex pregnancies); (2) midwife model (i.e., midwife acting as primary provider of care); (3) shared care model (i.e., general practitioner-led care with hospital visits involving input from midwife or obstetrician) or (4) birth centre (i.e., a team of midwives who provide care). An 'other' option was provided.

\section{Statistical analysis}

To examine the representativeness of the sample, the age and gender of eligible responders and those giving birth in NSW [26] were compared using Chi-square analyses. Frequency data were used to describe the assessment and management of each health factor including: (i) the proportion of women who were screened for the risk factor; (ii) the proportion who indicated they needed assistance to manage the risk factor; (iii) the proportion who indicated they needed assistance and were offered it; (iv) the proportion who were offered assistance and accepted that assistance and (v) the proportion who accepted the assistance and found it was of benefit.

An overall screening adherence score was calculated by summing those factors women recalled being asked during their antenatal visit. This calculation excluded screening blood glucose levels and conducting a dating ultrasound as these assessments are not recommended for all pregnant women. Therefore the maximum achievable score was 21 . Missing responses were replaced with the individual's average for the remaining questions and those with over 3 missing responses were removed from calculations. To explore predictors of the overall screening adherence score, a multivariate quantile regression was performed on the median to account for the skewed outcome measure. The variables included in the regression model were: age, Aboriginal or Torres Strait Islander, country of birth, marital status, education, Socio-Economic Indexes for Areas (SEIFA) decile, with higher scores indicating higher socio-economic status. (Pink B. Socio-economic indexes for areas (SEIFA)-Technical paper. ABS Catalogue no. 2033.0.55.001. Canberra: ABS2011), private health insurance, model of antenatal care, any previous pregnancies, number of GP visits for pregnancy and number of tertiary antenatal visits. The variance inflation factor indicated no multicollinearity between the variables. The regression was conducted as a complete case analysis where those with missing data were excluded. Analyses were conducted in Stata 11.

\section{Results \\ Sample}

A total of 347 eligible women attending their second or subsequent antenatal visit were approached to complete the survey. Of these, 223 (64\%) consented to participate. The demographic and pregnancy characteristics of the consenting women are presented in Table 1 . The majority of women were in their third trimester ( $>25$ weeks of gestation) when they completed the survey $(75 \%)$ and $67 \%$ had had prior pregnancies. On average, participants were 20 weeks pregnant at their first hospital antenatal appointment $(\mathrm{SD}=7.1)$, had five general practitioner (GP) antenatal visits $(\mathrm{SD}=3.9)$ or hospital antenatal visits $(\mathrm{SD}=4)$ prior to completing the survey. Compared to the NSW birthing sample, those who completed the survey were younger $($ chi square $(\mathrm{df} 4)=19.0, p$ value $=$ 0.001 ) and more likely to be born in Australia (chi square $=55.7, p$ value $<0.001$ ) $[26]$.

\section{Women's self-reported rates of screening for clinical, screening and lifestyle risk factors}

Table 2 presents the proportion of women who were asked about each of the clinical, screening and lifestyle risk factors during their antenatal visits. Overall, $23 \%$ of women reported that they were asked about every risk factor in the ANC Guidelines $(\mathrm{m}=20.4, \mathrm{SD}=3.06$, Median $=21$, IQR $=18-23$, range 9-23). Women were frequently asked or enquired about blood pressure (99\%), smoking status (97\%), prescription medications (96\%), anxiety and depression (94\%) and alcohol intake (92\%). Fewer women reported being asked about oral health (32\%), diet (65\%) and weight gain (56\%). Of the 182 (86 \%) women who reported being asked about domestic violence, 176 (99\%) thought that the discussion took place in an appropriate context. 
Table 1 Demographics and characteristics of pregnancy for sample $(N=223)$

\begin{tabular}{|c|c|c|c|c|}
\hline & & Number & Percent & $\%$ for NSW in 2012(31) \\
\hline \multirow[t]{6}{*}{ Age } & under 20 & 3 & 1.4 & $3.1^{\mathrm{a}}$ \\
\hline & $20-24$ & 44 & 20 & 13 \\
\hline & $25-29$ & 71 & 32 & 27 \\
\hline & $30-34$ & 69 & 32 & 33 \\
\hline & $35-39$ & 24 & 11 & 19 \\
\hline & over 40 & 8 & 3.7 & 4.8 \\
\hline \multirow[t]{2}{*}{ Aboriginal or Torres Strait Islander Origin } & Yes & 12 & 5.4 & 3.4 \\
\hline & No & 209 & 95 & 97 \\
\hline \multirow[t]{4}{*}{ Marital status } & Married & 106 & 48 & \\
\hline & De Facto & 84 & 38 & \\
\hline & Never married & 23 & 10 & \\
\hline & Divorced or separated & 9 & 4.1 & \\
\hline \multirow[t]{2}{*}{ Speak English at home } & Yes & 215 & 97 & \\
\hline & No & 6 & 2.7 & \\
\hline \multirow[t]{2}{*}{ Born in Australia } & Yes & 197 & 89 & 65 \\
\hline & No & 24 & 11 & 35 \\
\hline \multirow[t]{2}{*}{ Private Health Insurance } & Yes & 68 & 31 & \\
\hline & No & 154 & 69 & \\
\hline \multirow[t]{3}{*}{ Highest level of education } & High School or below & 82 & 37 & \\
\hline & Trade or vocational training & 74 & 33 & \\
\hline & University degree & 66 & 30 & \\
\hline \multirow[t]{4}{*}{ Trimester at time of survey } & 1 & 1 & 0.5 & \\
\hline & 2 & 52 & 24 & \\
\hline & 3 & 166 & 75 & \\
\hline & given birth & 2 & 0.9 & \\
\hline \multirow[t]{4}{*}{ Model of antenatal care } & High risk & 100 & 46 & \\
\hline & Midwife & 55 & 25 & \\
\hline & Shared care & 56 & 26 & \\
\hline & Birth centre & 8 & 3.6 & 3.5 \\
\hline \multirow[t]{2}{*}{ Previous pregnancies } & No & 72 & 33 & \\
\hline & Yes & 145 & 67 & \\
\hline \multirow[t]{5}{*}{ Parity } & No births $>24$ weeks & 89 & 41 & $44^{\mathrm{b}}$ \\
\hline & 1 & 74 & 34 & 33 \\
\hline & 2 & 32 & 15 & 14 \\
\hline & 3 & 17 & 7.9 & 5 \\
\hline & $>4$ & 3 & 1.4 & 3.3 \\
\hline Total & & $223^{*}$ & & 98138 \\
\hline
\end{tabular}

${ }^{a}$ NSW data includes those younger than 18 which our study excludes. Comparison was conducted without this category

${ }^{b}$ NSW data counts birth from 20 weeks

*Missing data present so not all factors add to this total

Women's self-reported management of clinical, screening and lifestyle antenatal risk factors

Did women need help to manage risk factors?

Table 3 presents the proportion of women who indicated that they needed help to manage each of the clinical, screening and lifestyle risk factors. Overall, $70 \%(n=156)$ women reported needing assistance to manage at least one risk factor. Women reported needing help with managing their: weight (35\%), deciding which nutritional supplement to take (33\%), anxiety and depression (26\%) and 
Table 2 Proportion of all women who were asked about each of the lifestyle, clinical and screening health factors recommended in the ANC Guidelines $(N=217)^{*}$

\begin{tabular}{|c|c|c|c|c|c|}
\hline & $\begin{array}{l}\text { Asked about } \\
\mathrm{N}(\%)\end{array}$ & $\begin{array}{l}\text { Patient volunteered } \\
\text { N (\%) }\end{array}$ & $\begin{array}{l}\text { Never asked } \\
\mathrm{N}(\%)\end{array}$ & $\begin{array}{l}\text { Unsure } \\
\mathrm{N}(\%)\end{array}$ & $\begin{array}{l}\text { Prefer not to answer } \\
\mathrm{N}(\%)\end{array}$ \\
\hline \multicolumn{6}{|l|}{ Lifestyle factors } \\
\hline Smoking status & $208(97)$ & $0(0)$ & $6(2.8)$ & $1(0.5)$ & $0(0)$ \\
\hline Prescription medications & $206(96)$ & $0(0)$ & $5(2.3)$ & $3(1.4)$ & $0(0)$ \\
\hline Alcohol intake & $197(92)$ & $0(0)$ & $15(7.0)$ & $1(0.5)$ & $0(0)$ \\
\hline Recreational drug use & $190(89)$ & $0(0)$ & $21(10)$ & $2(0.9)$ & $0(0)$ \\
\hline Nutritional supplements & $173(80)$ & $8(3.7)$ & $25(12)$ & $9(4.2)$ & $0(0)$ \\
\hline Diet & $131(60)$ & $11(5.1)$ & $60(28)$ & $14(6.5)$ & $1(0.5)$ \\
\hline Oral health & $67(31)$ & $3(1.4)$ & $129(60)$ & $16(7.4)$ & $0(0)$ \\
\hline \multicolumn{6}{|l|}{ Clinical assessments } \\
\hline Blood pressure & $212(99)$ & - & $2(0.9)$ & $1(0.5)$ & - \\
\hline Anxiety and depression & $201(94)$ & $1(0.5)$ & $12(5.6)$ & $0(0)$ & $0(0)$ \\
\hline Dating ultrasound scan & $193(90)$ & - & $18(8.4)$ & $3(1.4)$ & - \\
\hline Previous, current mental health disorder & $189(88)$ & $0(0)$ & $22(10)$ & $3(1.4)$ & $0(0)$ \\
\hline Domestic violence & $182(86)$ & $0(0)$ & $29(14)$ & $0(0)$ & $1(0.5)$ \\
\hline Blood sugar & $177(84)$ & - & $27(13)$ & $7(3.3)$ & - \\
\hline Urine analysis & $179(84)$ & - & $28(13)$ & $7(3.3)$ & - \\
\hline Measure your weight & $174(82)$ & - & $34(16)$ & $5(2.4)$ & - \\
\hline Measure your height & $166(78)$ & - & $41(19)$ & $6(2.8)$ & - \\
\hline BMI (body mass index) & $108(51)$ & - & $71(33)$ & $34(16)$ & - \\
\hline Weight gain & $104(48)$ & $19(8.8)$ & $83(39)$ & $9(4.2)$ & $0(0)$ \\
\hline \multicolumn{6}{|l|}{ Screening } \\
\hline Down syndrome screening & $190(89)$ & $4(1.9)$ & $16(7.5)$ & $4(1.9)$ & $0(0)$ \\
\hline Rubella immunity testing & $172(81)$ & $0(0)$ & $32(15)$ & $9(4.2)$ & $0(0)$ \\
\hline Hepatitis B testing & $164(77)$ & $1(0.5)$ & $33(15)$ & $15(7.0)$ & $0(0)$ \\
\hline HIV testing & $155(72)$ & $2(0.9)$ & $39(18)$ & $18(8.4)$ & $0(0)$ \\
\hline Syphilis testing & $152(71)$ & $0(0)$ & $35(16)$ & $27(12.6)$ & $0(0)$ \\
\hline
\end{tabular}

* Denominators for the proportions were calculated removing missing responses. Minimum $N=211$

oral health (25\%). Fewer women reported needing help to manage alcohol intake (5\%), recreational drug use (5\%), prescription medication use $(7 \%)$ or domestic violence (9\%).

\section{Were women offered help to manage risk factors?}

Table 3 also presents the proportion of women reporting that they needed help to manage risk factors and the proportion that were then offered and accepted help to manage identified risks by providers. Women were more likely to be offered help to manage clinical risk factors such as anxiety and depression (85\%), mental health issues $(79 \%)$ and blood sugar levels (90\%). Women who reported needing assistance with managing lifestyle factors, such as weight gain, smoking, nutritional supplements and oral health, were less likely to report that they were offered help. Less than half of women who needed assistance reported they were offered help for domestic violence (47\%), prescription medications (43\%), alcohol intake (10 \%) and recreational drugs (27\%), however the number reporting a need for assistance with these issues was small (i.e., all $n<20$ ).

\section{Did women find the help they were offered beneficial?}

Women were less likely to accept assistance for domestic violence (50\%), smoking (63\%), mental illness (68\%) and anxiety and depression (68\%). The proportion of women who reported that the help they were offered was beneficial varied across health factors (Table 3). Fewer women reported that the help they received for domestic violence (50\%), recreational drug use (67\%) and smoking (67\%) was of benefit, however the number reporting they accepted help for these issues was small (i.e., $n<12$ ). 
Table 3 Proportion of women reporting needing help with health factors, being offered assistance, accepting help and finding the help beneficial

\begin{tabular}{|c|c|c|c|c|}
\hline Health factor & $\begin{array}{l}\mathrm{N}(\%) \text { needing } \\
\text { assistance* }\end{array}$ & $\begin{array}{l}\mathrm{N}(\%) \text { offered } \\
\text { assistance* }\end{array}$ & $\begin{array}{l}\mathrm{N}(\%) \text { accepting } \\
\text { assistance* }\end{array}$ & $\begin{array}{l}\mathrm{N}(\%) \text { finding } \\
\text { assistance helpful* }\end{array}$ \\
\hline Manage your weight & $74(35)$ & $27(36)$ & $20(80)$ & $16(80)$ \\
\hline Safety of nutritional supplements & $70(33)$ & $35(50)$ & $29(94)$ & $26(90)$ \\
\hline Help with anxiety and depression & $53(26)$ & $44(85)$ & $28(68)$ & $23(82)$ \\
\hline Improve your oral health & $53(25)$ & $7(13)$ & $5(100)$ & $4(80)$ \\
\hline Manage your blood sugar levels & $50(24)$ & $45(90)$ & $37(95)$ & $35(95)$ \\
\hline Manage an abnormal urine sample & $48(23)$ & $42(88)$ & $33(87)$ & $30(91)$ \\
\hline Quit smoking & $37(18)$ & $23(62)$ & $12(63)$ & $8(67)$ \\
\hline Help with mental illness & $33(16)$ & $26(79)$ & $15(68)$ & $12(80)$ \\
\hline Manage high blood pressure & $33(16)$ & $22(67)$ & $16(84)$ & $14(88)$ \\
\hline Help with domestic violence & $19(9)$ & $9(47)$ & $4(50)$ & $2(50)$ \\
\hline Stop taking unsafe prescription medications & $14(7)$ & $6(43)$ & $6(100)$ & $5(83)$ \\
\hline Stop drinking & $10(5)$ & $1(10)$ & $1(100)$ & $0(0)$ \\
\hline Stop taking recreational drugs & $11(5)$ & $3(27)$ & $3(100)$ & $2(67)$ \\
\hline
\end{tabular}

* Denominators for the proportions were calculated removing missing responses

\section{Predictors of overall screening adherence score}

The median number of risk factors that women recall discussing with their health care worker during antenatal care was $18(\mathrm{IQR}=15-20 ; N=211)$. The results of the multivariate quantile regression performed on the overall self-reported screening adherence score are shown in Table 4. Ten percent of the sample were missing at least one demographic variable and were excluded from the complete case analysis. After adjusting for covariates, women who were of Aboriginal or Torres Strait Islander descent and those who did not have private health insurance were asked about significantly more factors. Those who were receiving shared care between the GP and midwife were asked about significantly more risk factors, compared with those attending the midwife clinic alone.

\section{Discussion}

An apparent deficit by antenatal care providers to undertake routine screening or treatment for known antenatal risk factors and complications may contribute to potentially avoidable adverse maternal and fetal outcomes [27-29]. This is the first study to describe the rate of screening and treatment of risk factors as recommended in the Australian Health Ministers' Advisory Council Clinical Practice Guidelines: Antenatal Care from the perspective of pregnant women.

Antenatal visits are seen to represent a potentially powerful "teachable moment" for the promotion of healthy behaviours and the avoidance of adverse maternal and infant outcomes. Positive associations between adherence to recommendations and perinatal outcomes; and between the number of health promotion topics discussed and health behaviours during pregnancy have been reported [30, 31]. It is therefore promising that women in this study were frequently screened for risk factors such as smoking, alcohol intake, recreational drug use and domestic violence. However, less than a quarter of women self-reported that they had been screened for every risk factor. This is consistent with previous international studies. For example, approximately half of the women had $<80 \%$ of recommended ANC content documented in a Malaysian study [32]; while a USA study found that less than a third of women had $>80 \%$ of all recommended care documented [7].

Diet and weight gain during pregnancy and oral hygiene were relatively under-detected $[13,33]$. The breakdown in care at the point of detection is surprising given the increased use of forms in medical records that are used by providers in some antenatal clinics [22]. Further, the over-representation of women in their third trimester in this sample, with an average of five antenatal visits, suggests that there were multiple opportunities to screen for these risk factors. However, these findings are consistent with previous studies undertaken in both developing and developed countries, which report lower compliance for recommendations about health education and lifestyle behaviours compared to clinical and screening recommendations $[5,34]$.

Initiatives that have been successful in improving the accuracy and consistency of detection of health risks in other care settings, including primary care and oncology, offer a potential solution $[35,36]$. Such initiatives include systematic self-report assessments that can be completed by patients prior to visits with results reported directly to providers [35, 37, 38]; and patient-driven initiatives such as question prompt lists, which may increase the 
Table 4 Predictors of being asked about more health factors $(N=189)$

\begin{tabular}{|c|c|c|c|c|c|}
\hline Screen score & & Number & $\begin{array}{l}\text { Median health factors } \\
\text { asked about (IQR) }\end{array}$ & Coefficient (95 \% Cl) & $P$-value \\
\hline \multirow[t]{2}{*}{ Aboriginal or Torres Strait Islander Origin } & No & 179 & $18(15-20)$ & ref & ref \\
\hline & Yes & 10 & $20(17-21)$ & $2.084(0.147-4.021)$ & 0.035 \\
\hline \multirow[t]{2}{*}{ Born in Australia } & Yes & 172 & $19(15-20)$ & ref & ref \\
\hline & No & 17 & $17(16-19)$ & $-1.065(-2.776-0.645)$ & 0.221 \\
\hline \multirow[t]{3}{*}{ Marital status } & Married/ De Facto & 163 & $18(15-20)$ & ref & ref \\
\hline & Never married & 20 & $18(16-20)$ & $-0.056(-1.771-1.658)$ & 0.948 \\
\hline & Divorced or separated & 6 & $21(17-21)$ & $-0.386(-3.202-2.43)$ & 0.787 \\
\hline \multirow[t]{3}{*}{ Highest level of education } & High School or below & 66 & $18(15-20)$ & ref & ref \\
\hline & Trade or vocational training & 64 & $19(16-20)$ & $0.227(-1.03-1.484)$ & 0.721 \\
\hline & University degree & 59 & $18(15-19)$ & $0.117(-1.241-1.476)$ & 0.865 \\
\hline \multirow[t]{2}{*}{ Private Health Insurance } & No & 131 & $19(16-20)$ & ref & ref \\
\hline & Yes & 58 & $17(15-19)$ & $-1.29(-2.468-0.112)$ & 0.032 \\
\hline \multirow[t]{4}{*}{ Model of antenatal care } & Midwife & 45 & $17(15-20)$ & ref & ref \\
\hline & High risk & 92 & $18.5(16-20)$ & $0.888(-0.446-2.222)$ & 0.191 \\
\hline & Shared care & 45 & $19(16-20)$ & $1.699(0.202-3.197)$ & 0.026 \\
\hline & Birth centre & 7 & $18(15-19)$ & $0.692(-2.137-3.522)$ & 0.63 \\
\hline \multirow[t]{2}{*}{ Previous pregnancies } & Yes & 127 & $18(15-20)$ & ref & ref \\
\hline & No & 62 & $19(16-20)$ & $0.552(-0.6-1.705)$ & 0.346 \\
\hline Age & & & & $0.048(-0.058-0.154)$ & 0.373 \\
\hline \multicolumn{6}{|l|}{ Weeks pregnant } \\
\hline \multicolumn{2}{|l|}{ Number of visits to GP for antenatal care } & & & $-0.021(-0.134-0.091)$ & 0.707 \\
\hline \multicolumn{2}{|l|}{ Number of tertiary antenatal visits } & & & $0.083(-0.039-0.205)$ & 0.18 \\
\hline \multicolumn{2}{|l|}{ SEIFA } & & & $0.007(-0.004-0.017)$ & 0.232 \\
\hline \multicolumn{2}{|l|}{ Constant } & & & $9.23(-1.542-20.001)$ & 0.093 \\
\hline
\end{tabular}

frequency of question-asking by women and initiation of issues that providers may be reluctant or less skilled in raising $[24,39]$. Systematic reviews have identified a lack of time and relevant training as common barriers to detection of risk factors that are more likely to go undetected, such as poor nutrition and excessive weight gain [40-42]. Ongoing education and training for providers is needed, given the potentially adverse impact of undetected risks on maternal and fetal outcomes.

There were occasions where risk factors were identified but not managed well. Only two thirds of women in this study who indicated a desire for help to quit smoking report that they were offered this help, despite evidence for the effectiveness of smoking cessation interventions during pregnancy $[11,43]$. Strategies that can be implemented with minimal burden and facilitate point-of-care access to evidence based interventions to manage identified risks are critical. For example, providing point-of-care feedback to women and antenatal providers has the potential to guide visits and facilitate opportunistic intervention. Audit and feedback, reminders and multi-faceted approaches have also been shown to be particularly effective in obstetrics settings [29].

Less than half of women who indicated a need for help with domestic violence recalled being offered assistance by their providers. Misconceptions about risk factors, signs and symptoms, as well as a lack of time, training and effective referral pathways may contribute to poor detection and management of domestic violence [44]. These findings highlight the need for strategies to overcome identified barriers. Potential strategies might include: providing women with information about services that are available to help them if experiencing domestic violence (e.g., wallet-sized cards listing appropriate agencies, particularly refugees and sources of legal advice); providing education and training to antenatal care providers to aid them in discussing and responding to domestic violence; providing clear referral pathways and information about local services; enhancing collaboration between domestic violence agencies and antenatal care services (e.g.,., outreach with DV services providing in-service education and training) [44-46]. Ongoing education and training has been 
moderately successful in improving provider detection of domestic violence $[45,47]$. A recent Cochrane review has highlighted the need for further work in developing and testing programs to effectively prevent or reduce domestic violence [48]. As women may be reluctant to discuss issues again if a disclosure is mismanaged [24], this is an important gap that requires further examination.

Women also reported that they did not accept the help offered or did not find the help beneficial. While the numbers were small, this may have been due to the type of assistance offered or their readiness to change risk behaviour. For example, only $63 \%$ of women offered help to quit smoking accepted help. Similarly, of those requiring assistance for anxiety and depression, $59 \%$ were offered a referral to a mental health specialist, however $14 \%$ did not accept the referral. Studies in primary care populations suggest that patient views about the acceptability of psychological treatment is a key factor in poor uptake. People who receive treatment that matches their preference recover more quickly than those who perceive a mismatch between their preferred and received treatment [49]. Therefore, information about patients' perceived needs and preferences for treatment are likely to be an important adjunct to information on severity of the risk factor. Even when interventions are accepted, desired outcomes or behaviours may not always be achieved. Monitoring risk factors over time may highlight those areas where previous intervention efforts are unsuccessful. The application of higher-intensity interventions tailored to individual needs may be required. 'Steppedcare' approaches have had some success in the treatment of risk factors such as depression [50].

This study identified sub-groups of women who were more likely to be screened for a greater number of risk factors. Women of Aboriginal and Torres Strait Islander descent were asked about more risk factors. While this is in contrast to previous studies which suggest this group are less likely to have issues identified [19], this may reflect an increased awareness of the adverse outcomes experienced in this population [51] among the treating team and subsequently concentrated effort to identify risk factors. Whether this identification of risk factors then translates into appropriate management for Indigenous women deemed at-risk requires further examination in a larger sample. Those without private health insurance were also asked about a greater number of health factors. Women who received shared care between the GP and midwife were asked about a greater number of health factors, suggesting an important role for GPs in maternity care [52]. The higher adherence rate reported by women receiving shared care may be due to a greater number of opportunities to be screened by multiple providers. It may also reflect individual-provider or clinic-level variation. Examination of variation at this level requires replication in multiple antenatal clinics and hospitals. The overall screening adherence score did not capture whether there were particular sub-groups who were more likely to be offered help or those who perceived the help was of greater benefit. Previous studies have shown that there may be variability in the follow-up of identified risk factors for some sub-groups [53]; and particular sub-groups for whom interventions are less effective [54-56].

\section{Limitations}

This study was undertaken in a public hospital in Australia, with both high and low risk births and varied models of care. Adherence to recommendations in these guidelines should be examined in other antenatal care settings and with larger samples, to examine potential individual provider- and site-level variations in quality of care. Generalisation of these findings to other countries is cautioned, given that models of care and recommendations regarding the management of antenatal risk factors vary. For example, a recent systematic review of existing antenatal care (ANC) guidelines identified 15 routine ANC guidelines and 70 relating to specific situations or risk factors [57]. Of the 171 recommendations made in these guidelines, inconsistencies were reported for 33 recommendations [57]. There was also an overrepresentation of younger and Australian-born women in the sample. Women of non-English speaking background in developed countries such as Australia report higher unmet needs, lower satisfaction with care, suboptimal communication and health literacy and experience poorer perinatal outcomes [58]. Targeted approaches to quality improvement should be informed by perceived quality of care from the perspective of this vulnerable sub-group. We also did not examine the offering of assistance to those women who did not need it (e.g., provision of quitting advice to a non-smoker). Receipt of unnecessary health services may also contribute to evidence-practice gaps in health care and should be examined in the context of antenatal care [31]. There may also have been disparities between actual performance and women's self-reported performance. For example, women may under-report the need for assistance in some areas, such as alcohol intake or domestic violence. Integrating multiple data methods, including self-report, medical record audits and/or observation should be considered in future studies to confirm findings reflect actual variation rather than patient recall.

\section{Conclusion}

Pregnant women report suboptimal rates of screening and management of antenatal risk factors. Initiatives to improve consistency in detection of antenatal risk factors and the application of appropriate interventions to manage those risk factors that are detected are required. 
Quality improvement approaches involving systematic monitoring of risk factors combined with feedback to health care providers have been implemented in a range of care settings to reduce evidence-practice gaps and promote timely intervention. Such initiatives hold promise in antenatal care settings, however prospective identification of barriers and enablers to change is needed to help facilitate the success of such initiatives.

\section{Funding}

This research was supported by a Strategic Research Partnership Grant from the Cancer Council NSW to the Newcastle Cancer Control Collaborative. AW is supported by an Australian Research Council Discovery Early Career Research Award (DECRA). JB is supported by an Australian Research Council Post-Doctoral Industry Fellowship.

\section{Availability of data and materials}

Requests for anonymous data supporting the conclusions of this article should be addressed to the Health Behaviour Research Group, care of Dr Amy Waller: amy.waller@newcastle.edu.au.

\section{Authors' contributions}

AW contributed to study conception and design, data interpretation and critical revision of the manuscript for important intellectual content JB contributed to study conception and design, data interpretation and critical revision of the manuscript for important intellectual content. EC contributed to acquisition of data, data interpretation and critical revision of the manuscript. MG contributed to acquisition of data, data interpretation and critical revision of the manuscript for important intellectual content. JO contributed to data interpretation and critical revision of the manuscript for important intellectual content. RSF contributed to study conception and design, data interpretation and critical revision of the manuscript for important intellectual content. All authors approved the final version of the manuscript.

\section{Competing interests}

The authors declare that they have no competing interests.

\section{Consent for publication}

Not applicable.

\section{Ethics approval and consent to participate}

Ethics approval was obtained from the University of Newcastle Human Research Ethics Committee (HREC) and the HREC of the participating hospital (14/03/19/4.07; HREC/14/HNE/81). All pertinent study information was explained to participants and they were informed that refusal or withdrawal from the study would not affect their care. A study information sheet was given to all participants before obtaining their verbal and written agreement. Completion of the survey was taken as informed consent, and all responses were anonymous.

\section{Author details}

'Priority Research Centre for Health Behaviour, University of Newcastle \& Hunter Medical Research Institute, HMRI Building, Callaghan, NSW 2308, Australia. ${ }^{2}$ School of Medicine and Public Health, University of Newcastle, Callaghan, NSW, Australia. ${ }^{3}$ Department of Obstetrics and Gynaecology, Hunter New England Local Health District, Newcastle, NSW, Australia. ${ }^{4}$ Priority Research Centre for Reproductive Science, University of Newcastle, Callaghan, NSW, Australia.

Received: 4 February 2016 Accepted: 20 July 2016

Published online: 27 July 2016

\section{References}

1. Grol R. Successes and failures in the implementation of evidence-based guidelines for clinical practice. Med Care. 2001;39(8):II-46-54.

2. McGlynn EA, Asch SM, Adams J, Keesey J, Hicks J, DeCristofaro A, Kerr EA. The quality of health care delivered to adults in the United States. New Engl J Med. 2003;348(26):2635-45.
3. Grimshaw JM, Eccles MP, Lavis JN, Hill SJ, Squires JE. Knowledge translation of research findings. Implement Sci. 2012;7:50.

4. Pittrof R, Campbell OM, Filippi VG. What is quality in maternity care? An international perspective. Acta Obstet Gynecol Scand. 2002;81(4):277-83.

5. McDonald SD, Machold CA, Marshall L, Kingston D. Documentation of guideline adherence in antenatal records across maternal weight categories: a chart review. BMC Pregnancy Childbirth. 2014;14:205.

6. Nagpal J, Sachdeva A, Sengupta Dhar R, Bhargava VL, Bhartia A. Widespread non-adherence to evidence-based maternity care guidelines: a populationbased cluster randomised household survey. BJOG. 2015;122(2):238-47.

7. Handler A, Rankin K, Rosenberg D, Sinha K. Extent of documented adherence to recommended prenatal care content: provider site differences and effect on outcomes among low-income women. Matern Child Health J. 2012;16(2):393-405.

8. Maxwell S, Brameld K, Bower C, Dickinson JE, Goldblatt J, Hadlow N, Hewitt B, Murch A, Murphy A, Stock R, et al. Socio-demographic disparities in the uptake of prenatal screening and diagnosis in Western Australia. Aust N Z J Obstet Gynaecol. 2011;51(1):9-16.

9. Reilly N, Harris S, Loxton D, Chojenta C, Forder P, Milgrom J, Austin MP. Disparities in reported psychosocial assessment across public and private maternity settings: a national survey of women in Australia. BMC Public Health. 2013;13:632

10. McNamara TK, Orav EJ, Wilkins-Haug L, Chang G. Risk during pregnancy-self-report versus medical record. Am J Obstet Gynecol. 2005;193(6):1981-5.

11. Chamberlain C, O'Mara-Eves A, Oliver S, Caird JR, Perlen SM, Eades SJ, Thomas J. Psychosocial interventions for supporting women to stop smoking in pregnancy. Cochrane Database Syst Rev. 2013;10:CD001055.

12. Dodd JM, Grivell RM, Crowther CA, Robinson JS. Antenatal interventions for overweight or obese pregnant women: a systematic review of randomised trials. BJOG. 2010;117(11):1316-26.

13. Vamos CA, Thompson EL, Avendano M, Daley EM, Quinonez RB, Boggess K. Oral health promotion interventions during pregnancy: a systematic review. Community Dent Oral Epidemiol. 2015:43(5):385-96.

14. Flenady V, Macphail J, New K, Devenish-Meares P, Smith J. Implementation of a clinical practice guideline for smoking cessation in a public antenatal care setting. Aust N Z J Obstet Gynaecol. 2008;48(6):552-8.

15. Baxter S, Everson-Hock E, Messina J, Guillaume L, Burrows J, Goyder E. Factors relating to the uptake of interventions for smoking cessation among pregnant women: a systematic review and qualitative synthesis. Nicotine Tob Res. 2010;12(7):685-94

16. Halperin IJ, Feig DS. The role of lifestyle interventions in the prevention of gestational diabetes. Curr Diab Rep. 2014;14(1):452.

17. Australian Health Ministers' Advisory Council: Clinical Practice Guidelines: Antenatal Care - Module 1. 2012.

18. Carey M, Buchan H, Sanson-Fisher R. The cycle of change: implementing best-evidence clinical practice. Int I Qual Health Care. 2009:21(1):37-43.

19. Rumbold AR, Bailie RS, Si D, Dowden MC, Kennedy CM, Cox RJ, O'Donoghue L, Liddle HE, Kwedza RK, Thompson SC, et al. Delivery of maternal health care in Indigenous primary care services: baseline data for an ongoing quality improvement initiative. BMC Pregnancy Childbirth 2011;11:16.

20. Alati R. In Western Australia, $70 \%$ of mothers of babies with fetal alcohol syndrome did not have an alcohol-related diagnosis recorded during pregnancy. Evid Based Nurs. 2013;17:78.

21. Bollini P, Quack-Lotscher K. Guidelines-based indicators to measure quality of antenatal care. J Eval Clin Pract. 2013;19(6):1060-6.

22. Hawley $\mathrm{G}$, Janamian $\mathrm{T}$, Jackson C, Wilkinson SA. In a maternity shared-care environment, what do we know about the paper hand-held and electronic health record: a systematic literature review. BMC Pregnancy Childbirth. 2014;14(52):1471-2393.

23. Lewis SM, Cullinane FM, Carlin JB, Halliday JL. Women's and health professionals' preferences for prenatal testing for Down syndrome in Australia. Aust N Z J Obstet Gynaecol. 2006:46(3):205-11.

24. Webster J, Holt V. Screening for partner violence: direct questioning or self-report? Obstet Gynecol. 2004;103(2):299-303.

25. Zucca A, Sanson-Fisher R, Waller A, Carey M, Fradgley E, Regan T. Medical oncology patients: Are they offered help and does It provide relief? J Pain Symptom Manage. 2015;50(4):436-44.

26. Hilder L, Zhichao Z, Parker M, Jahan S, Chambers GM. Australia's Mothers and Babies 2012. Perinatal Statistics Series no. 30. Cat. no. PER 69. Canberra: AlHW; 2014. 
27. McDonald SD, Han Z, Mulla S, Beyene J. Overweight and obesity in mothers and risk of preterm birth and low birth weight infants: systematic review and meta-analyses. BMJ. 2010;341:c3428.

28. Hackshaw A, Rodeck C, Boniface S. Maternal smoking in pregnancy and birth defects: a systematic review based on 173687 malformed cases and 11.7 million controls. Hum Reprod Update. 2011;17(5):589-604.

29. Chaillet N, Dube E, Dugas M, Audibert F, Tourigny C, Fraser WD, Dumont A. Evidence-based strategies for implementing guidelines in obstetrics: a systematic review. Obstet Gynecol. 2006;108(5):1234-45.

30. Vonderheid SC, Norr KF, Handler AS. Prenatal health promotion content and health behaviors. West J Nurs Res. 2007;29(3):258-76. discussion 277-283.

31. Yeoh PL, Hornetz K, Dahlui M. Antenatal care utilisation and content between Low-risk and high-risk pregnant women. PLoS One. 2016;11(3):e0152167.

32. Yeoh PL, Hornetz K, Ahmad Shauki NI, Dahlui M. Assessing the extent of adherence to the recommended antenatal care content in Malaysia: room for improvement. PLoS One. 2015;10(8):e0135301.

33. Gaffield ML, Gilbert BJC, Malvitz DM, Romaguera R. Oral health during pregnancy: an analysis of information collected by the pregnancy risk assessment monitoring system. J Am Dent Assoc. 2001;132(7):1009-16.

34. Kirkham C, Berkowitz J. Listeriosis in pregnancy: survey of British Columbia practitioners' knowledge of risk factors, counseling practices, and learning needs. Can Fam Physician. 2010:56(4):e158-66.

35. Paul CL, Carey M, Yoong SL, D'Este C, Makeham M, Henskens F. Access to chronic disease care in general practice: the acceptability of implementing systematic waiting-room screening using computer-based patient-reported risk status. Br J Gen Pract. 2013;63(614):e620-6.

36. Bennett AV, Jensen RE, Basch E. Electronic patient-reported outcome systems in oncology clinical practice. CA Cancer J Clin. 2012;62(5):337-47.

37. Carey M, Noble N, Mansfield E, Waller A, Henskens F, Sanson-Fisher R. The role of eHealth in optimizing preventive care in the primary care setting. J Med Internet Res. 2015;17(5), e126.

38. Grady A, Carey M, Oldmeadow C, Bryant J, Mazza D, Sanson-Fisher R. GP detection of health risk factors among general practice patients at risk of primary and secondary stroke. Fam Pract. 2015;32(3):336-42.

39. Sansoni JE, Grootemaat P, Duncan C. Question prompt lists in health consultations: a review. Patient Educ Couns. 2015. doi: 10.1016/j.pec.2015.05. 015. [Epub ahead of print].

40. Nair M, Yoshida S, Lambrechts T, Boschi-Pinto C, Bose K, Mason EM, Mathai M. Facilitators and barriers to quality of care in maternal, newborn and child health: a global situational analysis through meta review. BMJ Open. 2014;4(5):e004749.

41. Nielsen KK, Kapur A, Damm P, de Courten M, Bygbjerg IC. From screening to postpartum follow-up - the determinants and barriers for gestational diabetes mellitus (GDM) services, a systematic review. BMC Pregnancy Childbirth. 2014;14:41-1.

42. Lucas C, Charlton KE, Yeatman H. Nutrition advice during pregnancy: do women receive it and can health professionals provide it? Matern Child Health J. 2014;18(10):2465-78.

43. Lumley J, Chamberlain C, Dowswell T, Oliver S, Oakley L, Watson L. Interventions for promoting smoking cessation during pregnancy. Cochrane Database Syst Rev. 2009;3:CD001055

44. Baird KM, Saito AS, Eustace J, Creedy DK. An exploration of Australian midwives' knowledge of intimate partner violence against women during pregnancy. Women Birth. 2015:28(3):215-20.

45. Baird K, Salmon D, White P. A five year follow-up study of the Bristol pregnancy domestic violence programme to promote routine enquiry. Midwifery. 2013;29(8):1003-10.

46. Phillips J, Vandenbroek P. Domestic, family and sexual violence in Australia: an overview of the issues. In: Research paper series. Parliamentary Libray. 2014 (http://parlinfo.aph.gov.au/parllnfo/download/library/prspub/4214443/upload_ binary/4214443.pdf,fileType=application/pdf).

47. Boursnell M, Prosser S. Increasing identification of domestic violence in emergency departments: a collaborative contribution to increasing the quality of practice of emergency nurses. Contemp Nurse. 2010;35(1):35-46.

48. Jahanfar S, Howard LM, Medley N. Interventions for preventing or reducing domestic violence against pregnant women. Cochrane Database Syst Rev. 2014;11:CD009414.

49. Lin P, Campbell DG, Chaney EF, Liu C-F, Heagerty P, Felker BL, Hedrick SC. The influence of patient preference on depression treatment in primary care. Ann Behav Med. 2005;30(2):164.
50. van Straten A, Seekles W, van't Veer-Tazelaar NJ, Beekman AT, Cuijpers P. Stepped care for depression in primary care: what should be offered and how? Med J Aust. 2010;192(11 Suppl):S36-9.

51. Murphy E, Best E. The Aboriginal Maternal and Infant Health Service: a decade of achievement in the health of women and babies in NSW. N S W Public Health Bull. 2012;23(3-4):68-72.

52. Sutherland G, Yelland J, Wiebe J, Kelly J, Marlowe P, Brown S. Role of general practitioners in primary maternity care in South Australia and Victoria. Aust N Z J Obstet Gynaecol. 2009;49(6):637-41.

53. Rumbold AR, Cunningham J. A review of the impact of antenatal care for Australian Indigenous women and attempts to strengthen these services. Matern Child Health J. 2008;12(1):83-100.

54. Passey ME, Bryant J, Hall AE, Sanson-Fisher RW. How will we close the gap in smoking rates for pregnant Indigenous women? Med J Aust. 2013;199(1):39-41.

55. Souza JP, Widmer M, Gulmezoglu AM, Lawrie TA, Adejuyigbe EA, Carroli G, Crowther C, Currie SM, Dowswell T, Hofmeyr J, et al. Maternal and perinatal health research priorities beyond 2015: an international survey and prioritization exercise. Reprod Health. 2014;11:61.

56. Heaman MI, Green CG, Newburn-Cook CV, Elliott LJ, Helewa ME. Social inequalities in use of prenatal care in Manitoba. J Obstet Gynaecol Can. 2007:29(10):806-16.

57. Abalos E, Chamillard M, Diaz V, Tuncalp Ö, Gulmezoglu AM. Antenatal care for healthy pregnant women: a mapping of interventions from existing guidelines to inform the development of new WHO guidance on antenatal care. BJOG. 2016;123(4):519-28.

58. Small R, Roth C, Raval M, Shafiei T, Korfker D, Heaman M, McCourt C, Gagnon A. Immigrant and non-immigrant women's experiences of maternity care: a systematic and comparative review of studies in five countries. BMC Pregnancy Childbirth. 2014;14:152

\section{Submit your next manuscript to BioMed Central and we will help you at every step:}

- We accept pre-submission inquiries

- Our selector tool helps you to find the most relevant journal

- We provide round the clock customer support

- Convenient online submission

- Thorough peer review

- Inclusion in PubMed and all major indexing services

- Maximum visibility for your research

Submit your manuscript at www.biomedcentral.com/submit 